\title{
Chapter 12 \\ Luxury as a Driver for New Urban Identities in Milan: Geographies, Spatial Practices, and Open Questions
}

\author{
Mario Paris
}

1 Abstract In contemporary cities, the role of capital and private investors who finance interventions in the field of urban regeneration has become an increasingly important catalyst for the physical and social impacts of these transformations. This paper aims to point out the role of urban projects developed by luxury companies or stakeholders in consolidated urban regions. Starting by analysing the spatial distribution of luxury firms in Milan and composing a tentative classification system based on a variety of case studies, the author proposes a mental map of spaces shaped, occupied, transformed and infected by the sector within the contemporary metropolis. The resulting network of urban places sprawls out not only across centralized areas, but also in peripheral neighbourhoods, which interact with existing contexts, spatial and economic relationships as well as evident and hidden flows. From this basis, the contribution reflects on a set of luxury-driven practices and their impacts on urban identities. The reflection includes the role played by media technologies in these transformations and in the study of their development. The conclusions then discuss the role of luxury; whether it transforms the physical form of our city (its shape and patterns) or rather influences processes of transformation.

Keywords Luxury • Identity · Global $\cdot$ Local · Urban

\subsection{Introduction}

As Amirtahmasebi et al. point out in their recent publication (2016; xxvii), 'every city has pockets of underused and underutilized land or distressed and decaying urban areas. These pockets of underused land weaken the city's image, livability, and productivity. They are usually the result of changes in the urban growth and productivity patterns. Urban regeneration policies either target inner city declining neighborhoods or vacant land parcels.' They define several different actions, developed through both public and private initiatives. Following an expansive phase where

\footnotetext{
M. Paris ( $₫)$

Urb\&Com Lab. - DAStU, Politecnico di Milano, Milan, Italy

e-mail: mario.paris@polimi.it 


\footnotetext{
${ }^{1}$ Over the last three decades, strategies promoted by the EC since 1986 to strengthen economic and social cohesion as part of its spatial development perspective (EC 1999) have played a key role. The relevance of this issue became evident thorough many documents published after the Lisbon Treaty (2007), such as the Green paper on Territorial Cohesion (EC 2008) and the Territorial Agenda (EU 2011).
} inhabitants, firms and capital move from consolidated urban cores to the exurbia (Soja 2000), current urban strategies reference the resulting urban regions as a whole system. Together with new, peripheral developments, private and public stakeholders have been experimenting with a variety of actions based on the re-activation of internal greyfields and brownfields that-in EU and Committee of Regions terms ${ }^{1}$ - we can refer to as 'integrate re-generation' of existing urban areas. The re-urbanization of certain areas of former industrial cities (factories, docks, ports, but also housing and abandoned public buildings) where warehouses became offices, residences and mixed-use neighbourhoods, which were improved through the development of 'individual', emblematic buildings where art, culture and creativity played a strong role as tourism and social catalysts.

This contribution explores the role of luxury within these transformations, going beyond the typical ideological approach found in academia. Scholars often oversimplify the complexity of this issue by pointing out only the economic processes related to these operations (capital multiplication and accumulation, risks of gentrification, segregation and discrimination). They have not taken into consideration their spatial influence nor other impacts of these actions related to socio-economic dimensions of their contexts. The research began from a set of questions that posited luxury-as an economic sector and as a system of values - as a producer of spaces-and their identities - through precise actions, techniques and networks based on specific intentions.

Since the middle-ages, producers of luxury goods have shown specific settlement strategies, where retail and other integrated functions typically colonize urban venues and, though only in a few cases, production remains confined to peripheral areas. Over the last decades, luxury players have increased their interaction with cities and local contexts, accentuating their spatial impacts. As pointed out in a recent publication (Paris and Fang 2018), consolidated settlement strategies of operators related with productive and business functions used to mainly affect central and preeminent locations-including main squares, high streets, etc. Their aim was to take advantage of the symbolic (quality of urban landscape, attractiveness and recognizability of the existing retail system) and physical qualities (proximity to markets and users, easy accessibility to providers and services). In parallel with these still ongoing processes, a set of changing socio-economic conditions (progressive saturation of markets, rise of alternative proposals based on good design + low prices, shifts in consumer's preferences from possession to sharing, need for investment diversification for luxury companies, etc.) have been pushing luxury actors to explore new forms of business and activities, resulting in new territorial influences. As the traditional approaches have been widely studied in cultural and urban studies, as well as in marketing and sociology fields, the impact of these new strategies must be explored, focusing especially on their impacts on urban identities. 
Therefore, this contribution is more than just a reflection on the results of alternative locations (peripheral, sub-urban, temporary) for luxury practitioners. The chapter aims to more deeply explore the current spatial practices in which the city and its socio-cultural, historical and environmental values became a testing ground for identities and local narratives to be used, created, integrated and exploited. Using Milan (I) and its recent transformations as a case-study, the chapter focuses on the processes of place making and creation of identities, pointing out the relationship between new functional systems (services, facilities) and the character of the city. The presence of luxury facilities enriches the traditional mental map of the city and contributes both to re-shaping processes and a new international image. Other urban transformations related to this 'luxury dimension' fit within the scope of the book as the involvement of several different protocols, media, and practitioners producing more than just goods or products come to involve luxury customers-as well as unwitting inhabitants- in a pervasive and original experience of places. For this reason, these operations often include a double dimension that mixes local features (traditional vocations, consolidate know-how and cultures, vernacular tastes) and global images and narratives (branding, wow-effect, the involvement of digital networks and communities of interests).

\subsection{Why Milan?}

In luxury studies at both a national and international level, Milan represents an important case study due to its longstanding tradition in the fields of fashion and design activities as well as because of a variety of transformations that have marked the city and its metropolitan area during the last decade.

Several Italian luxury brands are located in the city and many additional international groups have located their national headquarters in the city. Over the last year, the consolidated urban core, and its close periphery have become a testing ground for luxury firms proposing original retail formats, newly integrated offers and a range of spaces and venues. A set of facilities and functions sponsored or owned by companies involved in this sector have influenced the cultural and leisure offerings of the city and its attractiveness for local and international visitors. Moreover, in the planning field, Milan and its outskirts represent an interesting case. This area is a plural and polycentric space (Balducci et al. 2017; Paris and Balducci 2019), in which the central city and other consolidated small and medium settlements configure an articulated system. Interactions and mutual influences among these different elements mark this system. Moreover, this area is the only Italian urban region affected by a mature process of metropolitisation (Indovina 2007) since the end of WWII.

Due to the complexity and interactions of these factors, unpacking the territorial nature of the city represents a challenge as well as an opportunity for planners and scholars involved in luxury studies. 


\subsection{Methodology and Structure}

I explored these issues and practices through a dual methodology, a defining quality of this contribution. The first section, based on a geographic approach, consists of an interpretative reading of the spatial distribution of venues across Milan. The analysis of existing information regarding the three main industrial groups in the field of luxury produced a database that contains information about existing locations (function, address, activity, etc.). Subsequent geolocation processes produced maps that could point out settlement strategies of the firms and present an overview image through the overlay of these data. The second step involved the comparative-deductive method and exploration of existing literature regarding this issue, which supported a reflection linking Milanese cases with other national/international examples, allowing the definition of certain singularities in the settlement of these functions. Thanks to this dual approach, it is easier to show a geography of luxury within the city and select those areas where urban transformations-and related identities-depend on this sector. Having identified the field of study, the chapter focus on the processes, actors involved, and impacts related to these transformations, producing useful knowledge of this phenomenon. In the third section, I point out a set of open questions that should be answered in the next phases of the research and conclusions that reflect on how the impacts of these operations affect local identities of places, but also their liveability and how luxury-led transformations affect local inhabitants' 'right to the city'.

\subsection{Luxury as a Catalyst for New Urban Identities}

After three decades of luxury operators pushing for the expansion of their markets through a horizontal brand diffusion (globalization) and multiplication of their shops, in the last ten years they took a more integrated approach, developing several activities in parallel with their core business, based on selling goods and-in some casesservices. Observing the annual reports of the three main luxury goods companies by sales, according to the Global Powers of Luxury Goods Top 100 (Deloitte 2017), make this change clear.

As showed by Table 12.1, in 2007, the total revenues for these companies (LVMH Moet Hennessey-Louis Vuitton SE, The Estée Lauder Companies Inc. and Compagnie Financière Richmont) reached more than $€ 27.6$ billion through their more than 118 houses operating in different sectors (Wines and spirits, Fashion and leather goods, Perfumes and cosmetics, Watches and Jewellery, etc.) They nearly doubled profits by 2012 ( $€ 45.9$ billion) and by 2017 they reached just over $€ 64$ billion. In a socio-economic context marked by the financial crisis of 2008 with its far reaching impacts, these players consistently increased profits as well as their influence in economic and productive sectors along with industrial groups, as employers (Wierzba 


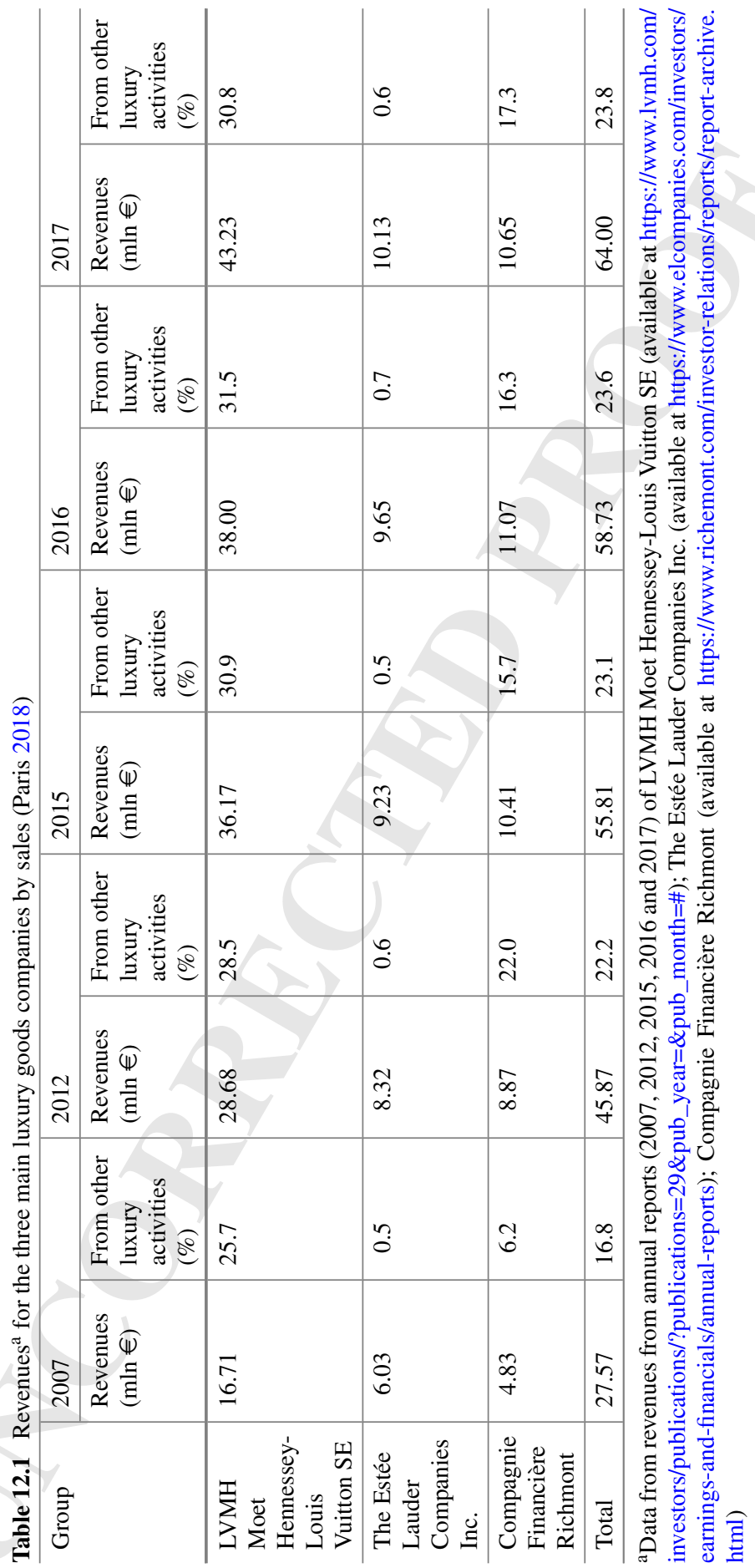

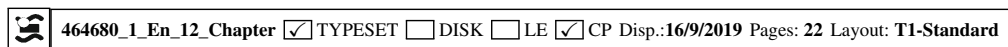


2015), attracting larger numbers of talented and specialized workers, while also expanding their role as landlords and real estate investors.

Together with the general increase of the total amount of revenues for these companies, luxury operations are usually classified as 'other activities', which comprises selective retailing, editorial activities, hotel/restaurant/café industries and food productions, and gained a significant role in the production sector. Their influence increased from $16.8 \%$ in 2007 to $23.8 \%$ in 2017 , which represents more than $€$ 15 billion over that period. In this chapter, I focus on the part of these performative activities that involve the transformation of urban spaces. In the following pages, I will present the processes in which luxury branding and financial strategies assumed a spatial dimension. As stated, up until now, this issue has been largely overlooked by urban studies.

In a recent publication, Paris (2018) together with a panel of distinguished colleagues from different backgrounds (urban and regional planners, sociologists, philosophers, architects, etc.) assumed that luxury companies have a relevant role in urban transformations. At times these actions are marked by a new sensitivity to places and contexts in which local tastes, their narratives and specific features serve as opportunities for businesses to attract customers and-ultimately—revenues. Luxury players have, for these reasons, come to integrate their traditional approach to urban space, in which they usually applied parasitic strategies (colonizing some of the most visible and important areas of cities by paying rents that other actors cannot afford), with innovative actions that follow a set of current trends in marketing, which affect social and moral approaches to this issue (Featherstone 2014). Today, luxury companies and firms are involved more than ever in urban changes through the economic, cultural and social activities that they develop in parallel with their strategies as industrial and financial actors (Paris and Fang 2018).

Luxury is one of the most abused words used to reflect upon current societies, a multibillion dollar global industry or used ubiquitously to describe exclusive objects and aspirational lifestyles (Kovesi 2015). However, defining the concept in concrete terms quickly becomes elusive and problematic. Luxury represents a cross-cultural semantic field (Dubois et al. 2001) which contains both productive actors (who create, manage and promote items), a set of values (self-affirmation, self-indulgence and pure exhibitionism) and savoir-faire. In this analysis I intend luxury as an agent of urban transformation. These two aspects are inseparable and-together-they influence spaces, lifestyles and the everyday routines of the people who live in them. One of the disruptive aspects of these luxury-driven actions on space is the ability of those companies to generate (and play with) both: a specific identity for places and a formal or material transformation of built objects that increase their appeal and attractiveness (and revenues used to sell goods and services). In this light, media and media technology has a specific role and influence both the experience of certain places and their projection on global imaginaries that increases their visibility. Luxury groups used to control the corporate identities and the global image of their brands, with marketing campaigns, global communications and advertisement through traditional and innovative channels. But nowadays, the social reputation of these enterprises interacts with feedbacks, data and images produced by users/customers-even if there 
are not usual luxury clients or testimonials. This process is even more evident for luxury spaces in cities that host inhabitants, tourists and city-users and they area a sort of living environment that users identify with specific brand. Therefore, media and media technologies influence the interactions of inhabitants with spaces, involving information, expectations and biases they influence not only the living practices of a specific space, but also the global image of its owner/developer. This original dimension is a new challenge for companies and the following sections will explore practices that have the power to create or play with specific identities reflecting about the geographies, spatial practices and open questions of this issue.

\subsection{Geographies}

As market players, luxury operators look for locations with different features, roles and connections within global networks and local contexts. Therefore, the analysis of luxury related spaces is not limited to shops and retail functions, but involves all those spaces where people think (creative workshop, ateliers), create and distribute (workshops, logistic spaces, warehouses), manage (as companies' headquarters, marketing, communication and administrative offices, foundations), exchange (flagship stores, thematic corners, showrooms dedicated to wholesalers or VIP customers) and consume (hotels, restaurants, lounges and facilities where specific products are used to provide premium experiences to users, art galleries and exhibitions centers) luxury goods, services and experiences (Fig. 12.1).

Mapping the settlement behaviors of the three main luxury groups in Milan creates an image marked by a distribution of venues across the city center with a major concentration in the historical core (Municipio 1) as well as several areas traditionally (Quadrilatero della moda around Via Montenapoleone, Corso Vercelli) or recently (Galleria Vittorio Emanuele, Via Dante, Corso Como) hosting premium retailers or services providers. A set of 'luxury hubs' (La Rinascente, Excelsior Milano, Coin) includes several corner shops and concessions that have become specialized attractors for luxury customers within the whole system.

212 activities and 34 buildings/containers compose the sample, in which uses relate with the selling and exchange of luxury goods (164 elements and 8 containers). These activities are the most diffused, followed by those dedicated to the consumption of exclusive services and products (craftsmanship, restaurants, café, bars, etc.), represented by 44 activities. Following a traditional vocation of the city, two venues relate to the production of goods and others to luxury experiences ( 2 activities and 8 buildings) (Fig. 12.2).

From a spatial point of view, this first interpretative geography shows several trends related to the actions of luxury operators in the city:

- The strong interest towards activities located in the central core of the city where there are processes of concentration and specialization—regarding merchandizing 


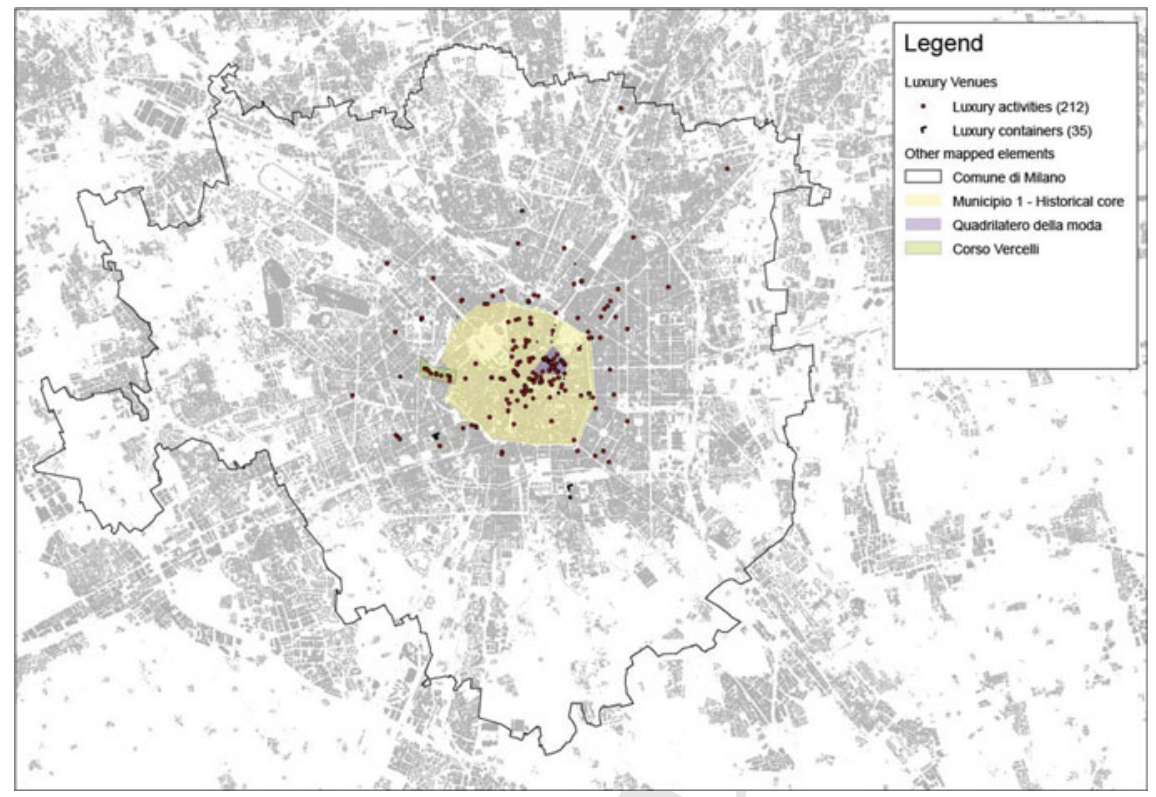

Fig. 12.1 Venues of the three main luxury groups in Milan (I)_-Paris (2018)

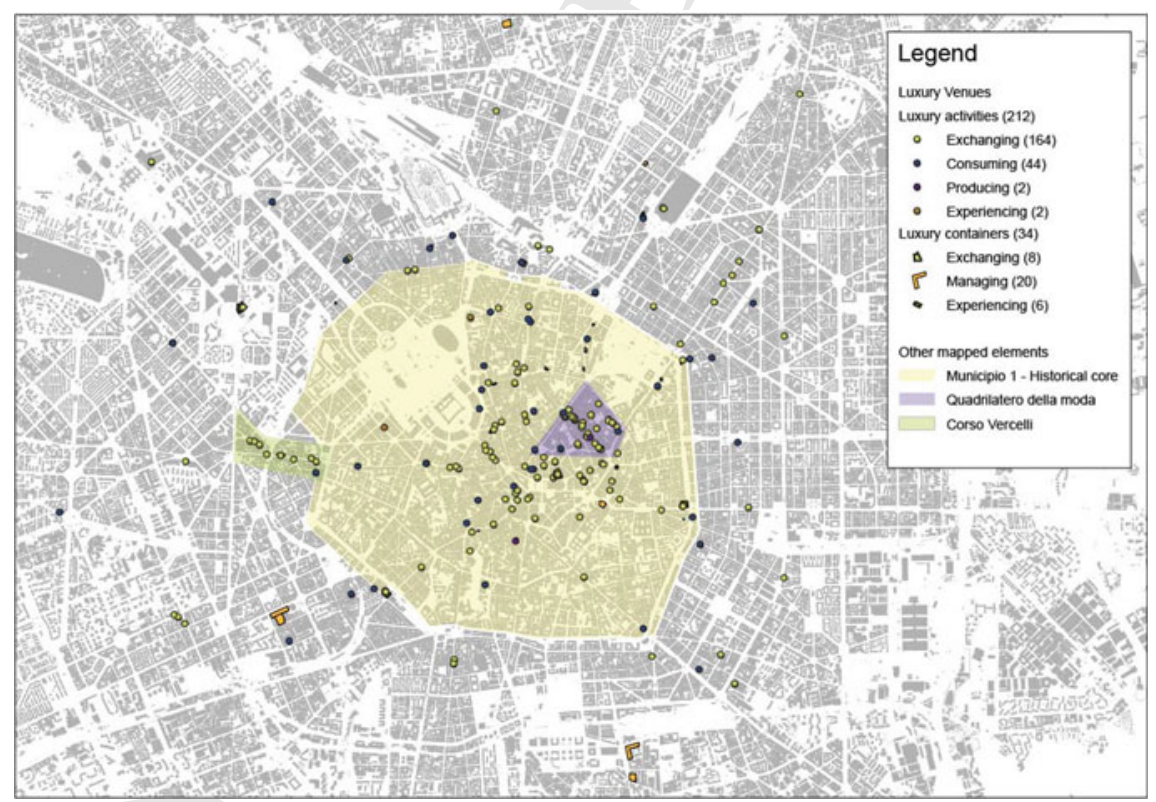

Fig. 12.2 Functions and roles of different venues of the three main luxury groups in Milan (I) Paris (2018) 
and offer—of specific areas (Quadrilatero for fashion, via Dante for Cosmetics and make up, etc.);

- Progressive colonization of the first peripheral area, with functions that support the groups' activities, such as the largest headquarters or showrooms dedicated to professional buyers. These compounds, marked by specific logistic related needs, accessibility, and relationships with partners and clients, often re-use industrial spaces and existing urban spaces, improving the process of transformations in this part of the city;

The definition of relationships that connect the high streets (Quadrilatero, Corso Vittorio Emanuele, Via Dante, Brera, Corso Como) and emerging hubs (La Rinascente, Brian and Barry Building, Coin Excelsior and Galleria Vittorio Emanuele) has created a new pathway within the central core of Milan, one that connects different neighbourhoods and links traditional venues with new presences.

These trends are confirmed by also looking at the spatial distribution of venues from an operative point of view. Luxury groups often maintain an independent or direct control on the venues located in areas of consolidated prestige or symbolic value, leaving other players to colonize the periphery, operating through collaborations or concessions.

An experimental approach is often developed by supporting several activities through sponsorships or choosing several dynamic actors that became 'ambassadors' of the brand or group. In this way, the presence of luxury operators in not-usuallyprestigious locations shows different and integrated strategies of these stakeholders: testing new locations without direct involvement, brand promotion linked to specific events, place-marketing, etc. (Fig. 12.3).

All of these strategies are not uniform or transversal, rather they depend on the behaviours and settlement approaches of individual operators. Focusing in on the situation of each group reveals that luxury brands generally compete for spaces located in central areas or on important high streets, colonizing ground floor stores and whole buildings with their showcases and exhibition functions (showroom). At the same time, the Compagnie Financièere Richmont concentrated the main stock of its venues in several spaces close to the Duomo, but the company established its headquarters in the northern part of the peripheral area. On the other hand, the LVMH group's headquarters are sprawled across different locations, both central and peripheral areas, with a high presence in southern neighbourhoods (Via Ripamonti and Via Tortona) and buildings dedicated to specific sectors (such as wine and spirits or jewelleries' presence can also be found in luxury containers owned by other groups (such as La Rinascente, Coin or within the new 'CityLife Shopping District', a new shopping mall located within the former Fiera Milano that houses different initiatives along with bars and restaurants). The Estée Lauder Companies group used a third strategy, one more pervasive and diffused across the city, due to its specific offer, primarily cosmetics and products that can be sold by concessions and different retailers, not only in dedicated showrooms (Fig. 12.4).

The result is a complex variety of approaches, that together with the presence of other competitors (as Luxottica Group Spa, Kering SA, or Prada, Armani and 


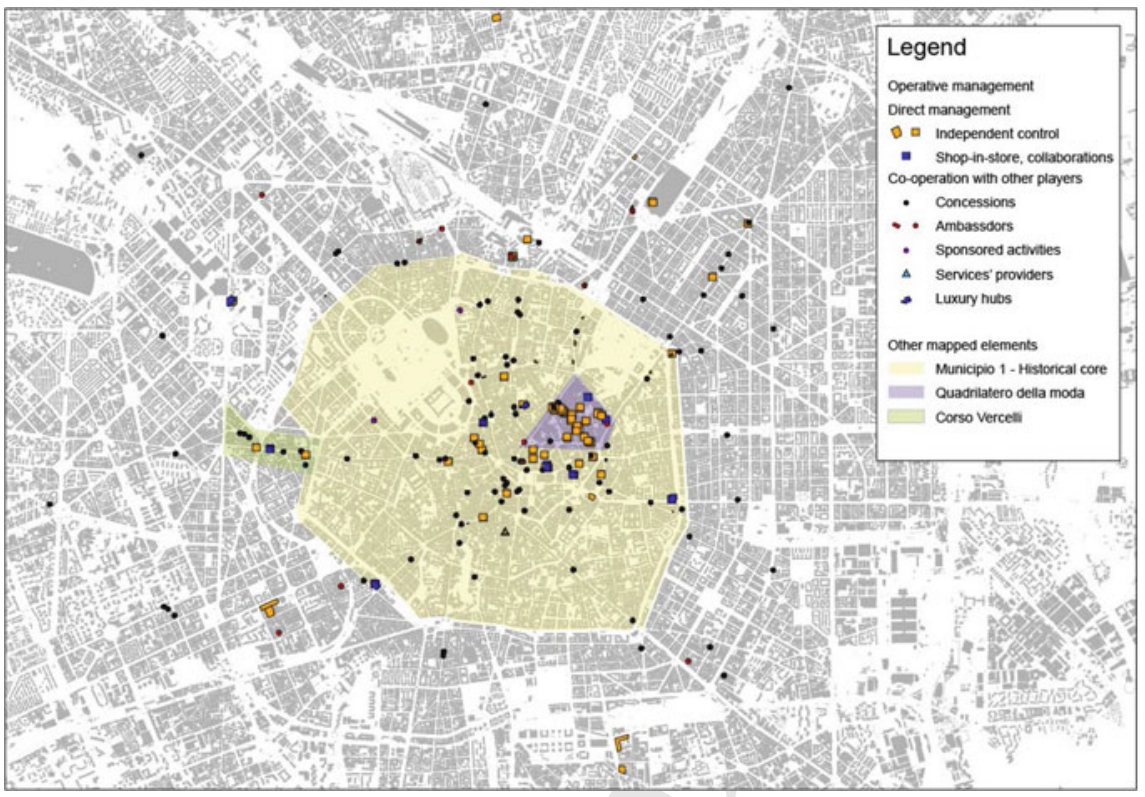

Fig. 12.3 Management and ownership of different venues of the three main luxury groups in Milan (I)-Paris (2018)

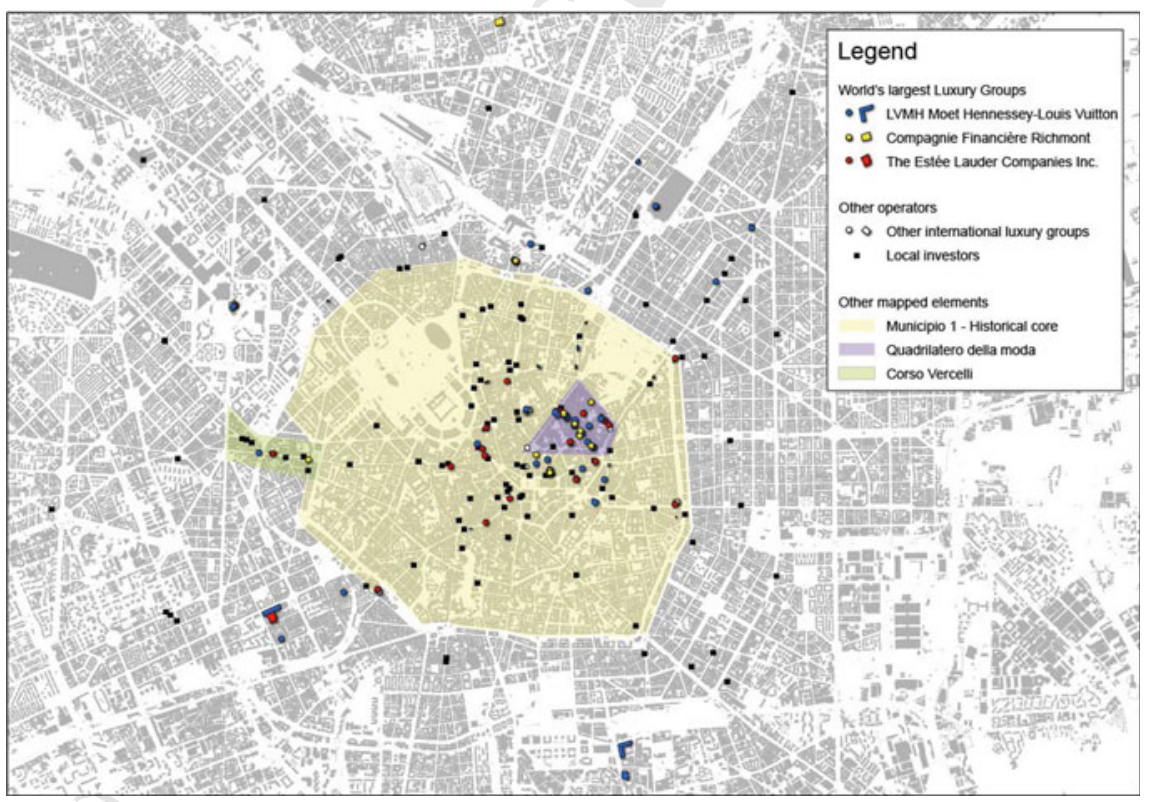

Fig. 12.4 Brand diffusions and spatial competition of different venues of the three main luxury groups in Milan (I)—Paris (2018) 


\footnotetext{
${ }^{2}$ According to these two authors who quote Berry's work (1994), the perception of luxury has altered across the centuries from being an effectively negative connotation-based on the classical philosophical paradigm constructed by Plato (2007), the Romans and early Christians who refer to 'the lust' as a capital vice - to a perception of 'well-being' in terms of economic wealth (Smith 1982) or due to the superior quality of goods, experiences or services and their esthetic or material conditions, design and overall quality of their productive processes.
}

As pointed out by Miller (2017), luxury productions and consumptions have been part of urban functions since early in the modern era (Kovesi 2015) thanks to a de-moralisation ${ }^{2}$ process of wealthy lifestyles (Roberts and Armitage 2018) that led to an increase in the relationship between premium consumption and urbanized territories. The location of nobility and the growing upper middle class in cities following the industrial revolution represented a targeted reference point for the producers and retailers of premium goods. In this way luxury companies colonized urban spaces, according to specific needs related with productive and logistic aspects, such as the presence of specific know-how or specialized professionals, but also due to the visibility of operators and display of customers. Historians and sociologists studied these phenomena, pointing out typical behaviours, their evolution over time and in different cultural contexts. Despite this large number of studies, only a few researchers studied the spatial influences of the settlement strategies of luxury players in cities and the location patterns of premium functions, especially at a moment in which these actors changed their spatial approaches. In this way, the spatial dimension of luxury-driven urban transformations needs to be overhauled and supported by studies developed in the last few years and return to an empirical observation of current practices ongoing in urban regions. As explained in the introduction, this chapter tests this approach in the city of Milan and its urban area, which contains many examples of recurrent practices that can be compared with other Italian or international cases. At the same time, the complexity of this field is due to a set of factors that must be included in the analysis, which I used to classify several examples, providing a tentative classification system that considers the role of these spaces in the definition of the identity of places: 


\subsection{Dealing with Existing Local Identities}

Historical settlement processes for luxury functions has produced, over the centuries, consolidated clusters, districts or punctuated presences in cities and broader urban areas. The inertia of these systems influences context in many ways. On the one hand, it impacts the specialization of some areas of Milan that, over time, have become part of a global geography of luxury destinations. Examples include the system of Via Montenapoleone and Via della Spiga in the city centre or Corso Vercelli that represents linear systems formed by fashion brands with their flagship stores and local dealers which includes other examples like the international Rue du Faubourg Saint-Honore in Paris or the 5th Avenue in New York or Rodeo Drive North in Beverly Hills (CA). In parallel, containers such as La Rinascente in Piazza Duomo or Excelsior Milano in Galleria del Corso are specialized department stores located in prominent buildings and represent key shopping destinations. In international examples we find the historical venue of Grand Magasins La Samaritaine in Rue de Rivoli (Paris) - currently under a controversal process of refurbishment developed by LVMH group —or GUM Department Store (Glavny Universalny Magazin) in Red Square (Moscow).

These examples show how this kind of function creates a specific character for urban spaces, that can become recognizable worldwide, even by those not involved in premium consumption. At the same time, these cases indicate how the consolidated strategy for luxury companies is based on the colonization of central areas, taking advantage of the symbolic values of these spaces, the quality of the urban fabric and the presence of vibrant public space. Therefore, the analysis of luxury action in cities must start from these systems, which interact with mainstream living practices of cities, with consolidated flows and agglomeration of people and that often coincide with those places marked by a specific identity—suggested by recognized landmarks—or 'aura' (Castello 2010).

Luxury companies developed in these areas through different actions that concern both what was taking place within their private spaces and in the exterior public realm or within some usually-closed off spaces that can be opened to host events and happenings during specific moments. For example, Burberry used its flagship store on Regent Street in London in 2017 (Scott 2017) as a venue for live events/concerts or streaming projections of runways. In many such cases, operators involve public spaces in these operations, supporting pop-up shops or temporary installations not devoted to the selling of goods, but rather to promote the brand's image or its social role. In Milan, the colonization of spaces often follows the agenda of Fashion or Design weeks, where the public has free access to show rooms, shops or private palazzi (palaces), such as Palazzo Bocconi during the Design Week 2018.

In general, these actions interact with the ordinary operation of the places, transforming them through non-banal actions including the insertion of art pieces, pedestrianizing streets, changes in the urban rhythm, etc. which influence the living practices of their inhabitants. These exceptional events are usually powerful and highly 
visible. In some cases, these actions became more radical and influenced the permanent transformation of these spaces, altering their materiality and producing solid traces of branding strategies, which occurred at the Galleria Vittorio Emanuele in Milan, where the refurbishment was financed by the municipality along with the revenues from the luxury companies (Prada, LVMH, Versace) that rent the retail spaces within.

\subsection{Exploiting Local Identities in Global Markets}

Specific market approaches and commercial strategies developed by luxury companies often differentiate their settlement choices according to the brand image and purchasing power of the different houses that take part in their industrial groups. ${ }^{3}$ Therefore, they colonize distinct parts of the city with specific functions and brands, showcasing different abilities to interact with places and proposing specific attitudes related to local features and characteristics. In some cases, they interact with local conditions and specific 'tastes'. Therefore, as will be seen in the following sections, specific urban identities, related to specific cultural presences, history and traditions became an asset for the promotion of certain brands.

This field is multifaceted and started with the simple relationship between a national, cultural and consolidated identity that guaranteed quality and an added value related to a local tradition or consolidated know-how about specific aspects of the production process. One of the most recognized examples is the power of 'Made in Italy' certification for food and fashion or 'Made in Switzerland' for watches. Many luxury brands have adopted a similar strategy, like Acqua di Parma, Donna Karan New York, Jo Malone London, etc. where a name or city recalls a specific background or imaginary for customers. However, this chapter focuses on a smaller scale, in which the identity and the image of specific places or landscapes became the added value — or asset - for luxury operators. In this sense, the case of Luisa Via Roma, one of the global leaders in the online luxury market, who took the brand name from the address of their first physical shop in Florence. Its website nowadays is its main platform, where clients make contact and purchase goods from a selected list of products, as the retailer serves as a sort of curator that recreates a specific 'Florentine' style.

Amongst Milanese examples, 10 Corso Como represents a key case in this field. This concept store opened in 1990 as a photo and art gallery in a former garage located at the address Corso Como 10. One of the key concepts of this case is that the location was on the border of the historical city centre, just outside of the Porta Nuova Gate. This area is well connected with consolidated high streets (Corso Garibaldi

\footnotetext{
${ }^{3}$ As explained in the previous section, the three luxury companies selected for the study are: LVMH Moet Hennessey-Louis Vuitton SE that operates 70 different houses; The Estée Lauder Companies Inc. with 30 and Compagnie Financière Richmont with 18 . These houses belong to several different sectors (Wines \& Spirits, Fashion \& Leather Goods, Perfumes \& Cosmetics, Watches \& Jewellery, Selective retailing and Other activities) and every company has its own specialization practices.
} 
and via Brera) and dynamic spaces that were - at that time - under a process of regeneration through the insertion of new functions (the new venue of Fondazione Feltrinelli, Gae Aulenti square and the new towers around the Varesine area as well as the Bosco Verticale that hinges with the Isola neighborhood). The idea, developed by C. Sozzani-fashion editor and publisher-evolved over the years, also thanks to the collaboration with American artist K. Rush that produced the brand identity and a recognizable image. More and more functions were added to the space's program from the inclusion of a roof-garden for events, a café, a bookshop, a fashion store (called 10 Corso Como) to a three room hotel. In parallel, the parent company developed a marketing strategy based on (i) producing collections of eau de toilette, clothes and accessories collaborating young designers with its brand; (ii) increasing the visibility of the concept store, through the quality of the publications of its own publishing house and the relevance of the exhibitions and events hosted in its spaces. Furthermore, in association with Comme de Garcon, it opened a store in Tokyo (JPN) in 2002 as a testing ground for the future expansion of the concept in other countries. This process produced a strong recognisability for the 10 Corso Como brand, which attained global visibility as a recognized hub for innovative design, thanks to the ability of C. Sozzani to perceive new trends and support talented creatives. In 2008, thanks to a joint venture with Samsung, they started several openings in Asia (Seoul, Shanghai and Beijing) and the US (New York).

This example shows how a specific identity, based on peculiar 'tastes', traditions and features can become a sort of product where the history and the tradition of a region, a city or a neighbourhood certify the authenticity, the quality and link with a specific imaginary. Often in luxury, investors exploit this imaginary in order to take advantage of it in commercial terms and to reinforce the brand image (as Prada did by introducing the name 'Milano' - in Italian —in its logo or Fendi with 'Rome' or a general recall to a Southern Italian imaginary developed by Dolce e Gabbana in their recent ad campaigns). In extreme cases, the identity of a place became a brand itself as well as an asset for private actors. Many experiences have explored this dimension, in which global companies play with the local dimension by interacting with autochthonous entrepreneurs and other figures or developing specific offers where products acquire a specific design or image influenced by a local identity. The following step is to then exploit this mix within a global network, where customers - even if they have never been to a specific city being referenced-buy products that promote a particular place. In the process the 'must have' and 'must have been' mix and influence one another. This influence is a constant movement between real places and soft features, between hardware and software that emerge with even greater force thanks to new media, technologies and social networks producing original and interesting combinations. Not by chance, the new showroom of Chiara Ferragni, the most famous Italian influencer and blogger, has been located within the Corso Como/Piazza Gae Aulenti urban system, producing an interesting interaction between digital networks and large urban transformations, where digital and physical dimensions are strengthened and acquire visibility thanks to their mutual interaction. 


\subsection{Defining New Identities for Places (At Different Scales)}

The current evolution of markets involves a multiplication of the spaces related to luxury industrial processes (production, distribution, promotion, etc.) and an enrichment of the offer of integrated functions. Therefore, settlement processes involve not only those centralized spaces traditionally related with affluent consumptions, but also peripheral areas that provide support and host functions related to business development. These transformations often take place in urbanized spaces, contributing to the processes of urban regeneration and involve underused buildings, urban voids, abandoned areas or greyfields, producing transformations that influence the city at different scales. Many examples involve the reuse of specific buildings: the Fondaco dei Tedeschi in Venice (developed by DSF), that regenerated a mediaeval trading post that had been transformed into a post office during the twentieth century. In Rome, the Palazzo della civiltà italiana in the EUR neighbourhood has been converted into the headquarters for the Fendi Group or the new venue of the Fondazione Alda Fendi Esperimenti that has been located in the Rhinoceros palace, a cultural hub designed by J. Nouvelle re-using a residential space close to the Piazza Bocca della Verità,

These spaces have become hybrid venues that now host different functions ranging from offices, art galleries, restaurants and cafés to public/shared spaces. In these cases, the transformations involved specific, iconic buildings that influenced the regeneration of a local context, beginning as an incremental process that triggered the production of a new image for a whole area, integrating them in a mental-map of luxury destinations for inhabitants and tourists. In Milan, the current transformation of Piazza Cordusio has brought about the progressive dismantling of several headquarters of banks and insurance companies to produce an opportunity for foreign investors to promote new settlement in luxury hotels and flagship stores.

These transformations tend to increase the complexity of the urban mix, inserting advanced services and specialized functions in contexts that usually lack urban vibrancy and attractiveness. In this light, while not ignoring the risks related with processes of over-valorisation (and gentrification) of urban contexts, such processes can represent an opportunity for cities and the local dimension, even if they require an innovative approach to governance that includes municipal and supra-local authorities (Paris 2018). In other cases, these dynamics exceed the scale of the building and involve entire urban compounds, that became new campuses or, at a different scale, new neighbourhoods. As pointed out, for many operators, these interventions represent something more than juts mere retail/commercial settlements.

International examples include the Miami Design District (Miami, FL) and the AC Tourism District (Atlantic City, NJ) in the US and in the European context, Battersea Power Station area in London (UK). In Milan, the recent opening of Armani/Silos (which contains the branded museum and company headquarters) joined the existing Armani Theatre — a venue for creative offices and runways - in the Via Tortona area. This project represents a sort of campus for the brand and the company selected 
this dynamic part of the city (close to the Fendi HQ complex and the headquarters of Ermenegildo Zegna) for the mix offered, where luxury integrates with the existing creative and cultural functions (Museo delle Culture-MUDEC, Superstudio, Magnolia Studios, etc.). Despite the rich presence of pre-existing small scale graphic and design offices, art laboratories and creative producers that re-used the industrial buildings found in this neighbourhood, luxury is not a rooted vocation for this context and represents another phase in the slow and incremental transformation of the neighbourhood. In two other cases, the Fondazione Prada venue in the southern area of Scalo Porta Romana — an abandoned railyard — and the Gucci Hub in Via Mecenate - a refurbished hangar - these compounds represent the initial driver for the transformation of their contexts. Located in the southern and eastern peripheries, where the edge of the modern city interfaces between housing and productive functions, these architectural systems, designed respectively by AMO-OMA and Piuarch, include management functions, communication and marketing offices, exhibition spaces and restaurants that aim to become a reference point for innovation in the Milanese context. These spaces acted as a pivot for a process of urban regeneration that has now exceeded their limits and involves different plots/areas surrounding their sites. Close to Fondazione Prada, other luxury headquarters, like that for the LVMH group, substituted productive functions together with the new venue of Talent Garden Calabiana and other showrooms and exhibition galleries in recent years. On the same plot of Fondazione Prada, the new smart neighbourhood 'Symbiosis', financed by the Municipality of Milan and developed through a European action, is taking shape and the abandoned railyard located in front of the site has been included as an area di trasformazione (development area) in new city masterplan.

In these cases, luxury stakeholders took on three main roles: first as an investor, when they promoted these operations. Then they served as an attractor as they generated new transformations in their contexts. Finally, they became a marketing device at a local and global scale, when they created a new image for a specific area of the city or by re-positioning a city within the global map of luxury destinations, impacting the real-estate market. All of these roles influenced the identity of places, while keeping their material memory as productive/industrial spaces, but developed, at the same time, a new urban role in which the brand image and the presence of a specialized working class and new flows of visitors/users of these spaces increased the complexity of existing neighbourhoods. At the same time, these campuses contribute to the processes of specialization and polarization of the city, increasing the differences between various neighbourhoods at an urban and metropolitan scale.

\subsection{Open Questions}

Nowadays, one of the most relevant fields of action for luxury players is urban space and the transformation of the city, due to its effectiveness in generating financial revenues, media values and marketing impacts. The exploration of such a complex issue and the focus on the influence of luxury in the definition of identities for places 
proposes a set of questions that affect both settlement strategies and placemaking practices, which researches have only partially answered.

Luxury-led transformations have traditionally been pointed out as producers of segregation, homologation and gentrification of urban spaces. Marked by a strong ideological approach, these critical readings have been useful categories to discuss traditional practices of luxury operators, when their actions have been oriented to the colonization of the most valuable and symbolic spaces of the city, marked by their scarcity, their inaccessibility to non-customer users and their high market price. However, current strategies of luxury groups also include processes of value generation related to the promotion of the brand (media value) and its relations with local contexts, far from consolidating speculative practices. In these operations, the experiential dimension assumes a relevant role and the expertise of luxury operators in creating attractive environments and evocative imaginaries is a key factor. As in their experimental shops/showrooms, operators used to work with the integration between different kinds of consumption (of goods, services and experiences) and various customers, an approach they applied to the urban scale. Together with these retail spaces, a variety of other functions supported the presence of these groups in the city and these aggregates all denoted spatial contexts and their vocations at different scales. As presented in the earlier maps, outputs are heterogeneous and faceted and they take place in different parts of the urban structure. Therefore, an interpretative approach to this complex group of experiences should be sensitive to and aware of the different strategies, actions and results, adapting current disciplinary tools and concepts to these new phenomena, marked by the prestige of their design and marketing solutions and not only for their exclusivity. This point is even more important in focusing on the characteristics and impacts of these aspects in the definition of the identity of these spaces and their effects on both physical and symbolic dimensions.

Other open questions affect the influence that professionals, technicians and developers have on the design and characterization of this identity. Luxury players show a consolidated knowledge in the promotion of a specific image and imaginary of a brand or a group through different kinds of mass media (press, radio and television and-more recently-internet), focusing on precise targets and showing a strong ability to adapt their individuality to local markets and cultural contexts. When they change their field of action, moving from shops and showrooms to the transformation of the city, they keep applying a set of strategies and protocols that use mass media to promote the brand and its role as status symbol in contemporary cities. In parallel, luxury players developed a communication - more subtle - based on luxury environments as extraordinary spaces, where users experiment experiences and events that are unique, taylor-made and ephemeral. This kind of communication mixes traditional marketing campaigns and other media, where social networks have a preminent role. Through these two channels, players promoted the image of specific brands, their qualities and their potential taking advantage of the involvement of users, customers and testimonials. This richness of stimuli represents an exciting challenge for planners and designers, especially when the promotion involves the city as a stage or container of peculiar-and luxurious-experiences. In some cases, their actions should maintain it and avoid the banalization characteristic of 

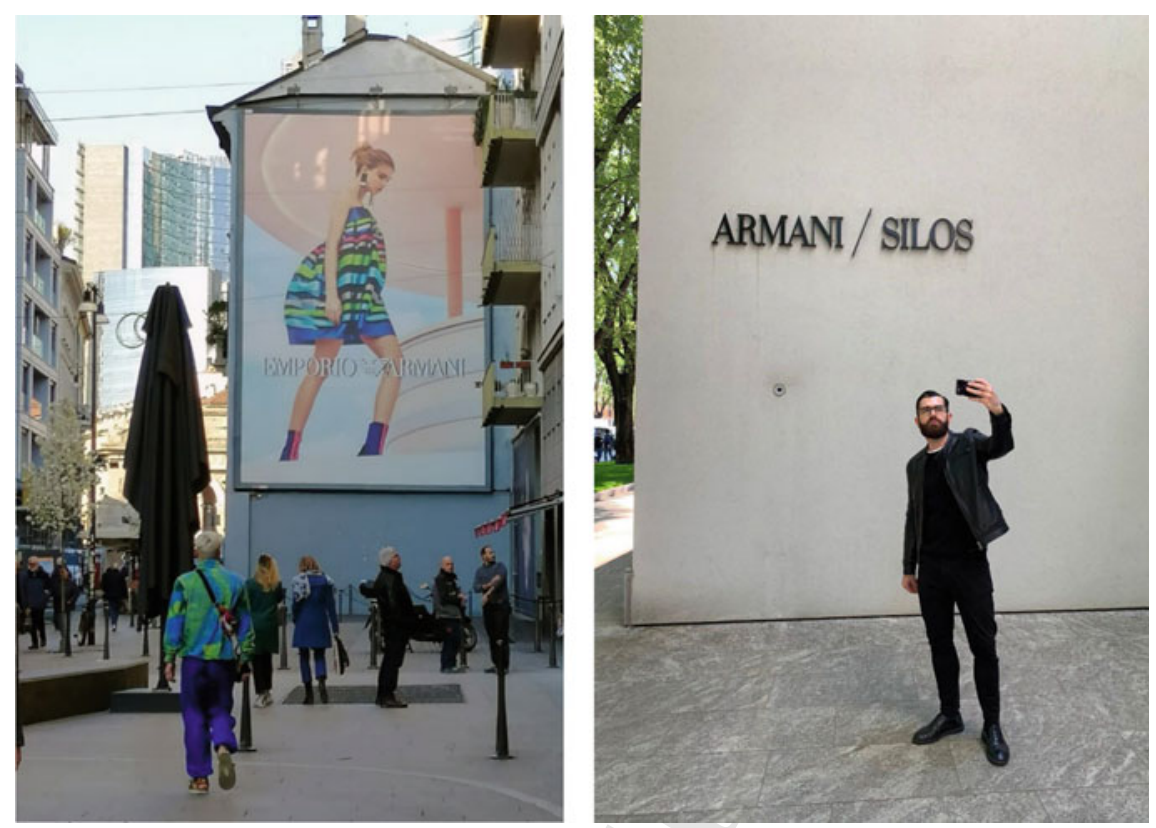

Fig. 12.5 Traditional marketing campaign and iconic urban projects as tools for the dissemination of brand images in Milan (I)—Venturi and Paris (2019)

current practices, where urbanity is simplified and imitated through trivial mimesis. We should focus on the approaches and the tools developed by operators of these luxury-led actions, pointing out where and how they can produce places able to host spontaneous uses of the spaces, social encounters and interactions (Fig. 12.5).

Exploring specific cases and best practices could be an important contribution to the planning discipline by producing a specific knowledge useful for those responsible for planning and governing similar transformations as well as for those operators that would like to develop innovative projects and actions.

Finally, the analysis should take into account that luxury is one of the most dynamic urban factors that integrates a variety of parallel trends in cooperation with defining local identities. Therefore, luxury-driven transformations of the city influence developers, their markets and the public actors involved, but also anyone who uses and inhabits the space (inhabitants, tourists and city users), not only luxury customers. The analysis of their spatial distribution shows a complex system formed by luxury activities and buildings that interact and overlay other systems of other urban functions. Forms and intensity of the relationship between luxury and non-luxury activities mark the vocation of a specific area of the city, influencing its physical reality (defined by materials, permeability, public space distribution, etc.) and the mental maps of those who inhabit these spaces. Research in this field should explore this dual dimension, which will influence the quality of life of inhabitants and their everyday experience of the city. 


\subsection{Conclusions: The Open Relationship of Urban Identities and Luxury}

This contribution discusses the role of luxury and the groups involved in this economic sector as transformers and producers of identities within the city. Through the analysis of an articulated atlas of spatial practices in Milan, I point out that luxury acts as a catalyst for the physical transformation of several fragments of the urban system. On the one hand, a set of interventions - based on exclusiveness-highlights the interest in the most attractive and iconic spaces of the city. On the other hand, a variety of transformations located in semi-central or peripheral spaces dedicated to a set of integrated activities (culture, leisure, art, management, etc.) and not only for retail, represents an original trend for these operators.

Therefore, luxury stakeholders deal with the local identities of their current interventions in cities and these identities influence the material results of their actions. Peculiar tastes of a city or a neighborhood are promoted as a factor that people enjoy to stay in or to visit specific locations, and they became part of the desire that those companies try to satisfy. The local dimension becomes part of the uniqueness and the added value of the experience that can be achieved through consuming - as a customer or simple user-in a specific place. At the same time, luxury groups are able to involve the genius loci of urban areas in their marketing campaigns, playing with specific aspects and their impact on the global imaginary. In this light, Paris became 'romantic', Milan 'fashionable', Berlin 'bohemien', etc. in their advertisements, and those aspects supported the promotion of their products worldwide, even if they lack a geographic connotation. In both processes, luxury stakeholders shape and frame the features that characterize the identity of places, producing opportunistic mediations and mediatisation, often far from the original intention.

In a society where consumption is pervasive, and firms operate globally, the interaction between local images, lifestyles, varieties of a city-in one word, its urbanity - and a brand, with its products and its customers, provides a strong and ephemeral value to commodities. Luxury brands take advantage of this relationship, stressing the idea that a luxurious consumption is also placed-based, a sort of contemporary ' $h i c$ et nunc', that increases the extra-value and the scarcity of their products and involve the spatial variable in the customer experience. In this way, a city, a neighbourhood, a specific corner or public space can become part of the luxury consumption, integrating and increasing the brand power with their identity. According to Livingstone (2009; p. 3), mediatisation is 'a meta process by which everyday practices and social relations are increasingly shaped by mediating technology and media organizations'. To achieve this mediatisation, the identity of places is simplified in order to be communicated and shared with the audience, impacting its perception. The pictographic result is a set of iconic images or commonplace ideas about a space, through a synesthetic approach that uses a fragment of this identity to define an entire system.

Moreover, these luxury groups produce mediations between real urban spaces and their wealthy customers, projecting a sort of anticipation about a city, introducing a set of must-be or place-to-be that influences the practices of potential visitors. This 
process is not neutral nor harmless. It produces a narrative of the space that users will discuss, modify and re-produce at global scale. In this light, the city is influenced by this interaction: in terms of Sernini (1989) luxury developers point out, transform and create new identities or narratives about cities and in these operations, they take advantage of, simplify or stress-specific aspects, often mixing reality and fiction. If this practice is habitual for products and services, the impacts on spaces and urban compounds are controversial and not always free of negative effects on the liveability, quality and the usability of these places. This process is even more artificial when this precast character is promoted, adapted and sometime exported to other countries and cultures, producing a sort of fake imitation of specific lifestyles and living practices.

Media technology facilitates both mediations and mediatisation of the identity of places in many different ways. On one hand, the infrastructures that support the exchange of information and data accelerates the circulation of created or manipulated images, icons and opinions about definite locations. On the other hand, companies and customers interact with the space through technological devices and a significant part of their exploration of a place is based on the digital dimension and the mediation of a screen. Finally, technology produces a sort of continuous ability to practice several places (or the same place by different points of view) at the same time, producing a mosaic of spatial experience for luxury customers that actually belong to a specific community united by a specific interest.

Supported by technology, the relationship between luxury and urban identities is open and presents a strong evolution that depends on the companies' strategies. Over the last ten years, local tastes and practices, traditions and vocations of a restricted number of cities as an asset for premium firms, inhabitants and their lives, their social exchanges and their presence are not only public but becoming more and more part of the marketed product. Studies that focus on the spatial dimension of luxury actions on cities are the first step to deal with this issue and its socio-economic, territorial and political impacts.

\section{References}

Amirtahmasebi R, Orloff M, Wahba S, Altman A (2016) Regenerating urban land. a practitioner's guide to leveraging private investment. World Bank Group, Washington, DC. https://doi.org/10. 1596/978-1-4648-0473-1

Balducci A, Fedeli V, Curci F (2017) Post-metropolitan territories: looking for a new urbanity. Routledge, New York and London

Berry CJ (1994) The idea of luxury. A conceptual and historical investigation. Cambridge University Press, Cambridge, UK

Castello L (2010) Rethinking the meaning of place: conceiving place in architecture-urbanism. Ashgate Publishing Co., Farnham, UK

Deloitte (2017) Global powers of luxury goods 2017. Deloitte University, Antrepwen, B

Dubois B, Laurent G, Czellar S (2001) Consumer rapport to luxury: analyzing complex and ambivalent attitudes. Les Cahiers de recherche 33:1-56

EC (1999) ESDP-European spatial development perspective. Office for official publications of the European Communities, Luxembourg, LUX 
EC (2008) Green paper on territorial cohesion. European Commission, Brussels, B

EU (2011) Territorial agenda of the European Union 2020, towards an inclusive, smart and sustainable Europe of diverse regions

Featherstone M (2014) Luxury, consumer culture and sumptuary dynamics. Lux Hist Cult Consum 1(1):47-69. https://doi.org/10.2752/205118174x14066464962436

Indovina F (2007) The metropolisation of the territory. New territorial hierarchies. In: Font A (ed), L'explosión de la ciudad: Transformaciones territoriales en las regiones urbanas de la Europa Meridional. Ministerio de Vivienda, Madrid, E, pp 20-47

Kovesi C (2015) What Is luxury?: The rebirth of a concept in the early modern world. Lux Hist Cult Consum 2(1):25-40. https://doi.org/10.1080/20511817.2015.11428563

Martucci S (2012) Williamsburg walks. Public space and community events in a gentrified neighborhood. In: DeSena J, Shortell T (eds) The world in Brooklyn: gentrification, immigration, and ethnic politics in a global city. Plymouth, United Kingdom, pp 89-112

Miller LE (2017) Luxury in Europe 1600-1815: negotiating narratives 2010-15. Lux Hist Cult Consum 4(2-3):115-141. https://doi.org/10.1080/20511817.2017.1352221

Paris M (ed) (2018) Making prestigious places. How luxury influences the transformation of cities. Routledge, New York and London

Paris M, Balducci A (2019) Practicing a polycentric (post) metropolis. A dialogue about the Milan urban region. Inplanning, Groningen, NL

Paris M, Fang L (2018) From luxury to prestigious place-making: an overview. In: Paris M (ed) Making prestigious places. How luxury influences the transformation of cities. New York and London: Routledge, pp 1-20

Plato (2007) The Republic. Penguin Book, London, UK (380 B.C., ed)

Roberts J, Armitage J (2018) Luxury: from idea to the reality of prestigious places. In: Paris M (ed) Making prestigious places. How luxury influences the transformation of cities. Routledge, New York and London, pp 23-34

Scott A (2017) Part one; being the Burberry of public space: building an integrated experience. The urban developer, 26 Apr 2017. https://theurbandeveloper.com/articles/burberry-publicspace-building-integrated-experience-adam-scott. Accessed 30 May 2018

Sernini M (1989) I centri commerciali integrati in Italia. Quando il developer diventa urbanista. Archivio di Studi Urbani e Regionali 33:3-28

Smith A (1982) The wealth of nations. Penguin Book, London, UK

Soja EW (2000) Postmetropolis: critical studies of cities and regions. Wiley-Blackwell, OxfordChichester, UK

Wierzba L (2015) What is luxury?: Curating connections between the hand-crafted and global industry. Lux Hist Cult Consum 2(1):9-23

Mario Paris is an architect with a Ph.D. in Urban and Regional Planning. Mario is currently a research fellow at DAStU and member of Urb\&Com Lab in Politecnico di Milano, where he teaches Urban Planning in the AUIC School. As a researcher, he focuses on the spatial distribution of economic activities and their influences in urban/regional regeneration processes. 